\title{
Translational Profiles of Alpha 1-, Alpha 2-, and Beta-Globin Messenger Ribonucleic Acids in Human Reticulocytes
}

\author{
Susan H. Shakin and Stephen A. Liebhaber \\ Howard Hughes Medical Institute, and the Departments of Human Genetics and Medicine, \\ University of Pennsylvania School of Medicine, Philadelphia, Pennsylvania 19104
}

\begin{abstract}
In human reticulocytes, the critical balancing of $\alpha$ - and $\beta$-globin synthesis may be controlled in part by differential translation of the three major adult globin messenger RNAs (mRNAs), $\alpha 1$, $\alpha 2$, and $\beta$. In this study, we determined, as a parameter of translational efficiency, the relative ribosome loading of these three mRNAs. Using oligonucleotide probes specific for the $\alpha 1-$ and $\alpha 2$-globin mRNAs, we find that these two mRNAs have identical translational profiles. Their distribution contrasts with that of $\beta$-globin mRNA, which is present on heavier polyribosomes and is less prevalent in pre-80S messenger ribonucleoprotein fractions. The relative distribution of $\alpha$ - vs. $\beta$-globin mRNA is consistent with more efficient $\beta$-globin translation. In contrast, the parallel distributions of $\alpha 1$ - and $\alpha 2$-globin mRNAs suggests they are translated with equal efficiencies. Considering the relative concentrations of the two $\alpha$-globin mRNAs in normal reticulocytes, this result predicts a dominant role for the $\alpha 2$-globin locus in human $\alpha$-globin expression.
\end{abstract}

\section{Introduction}

Control over eukaryotic gene expression can be exerted in both the nucleus and cytoplasm. Nuclear events, including RNA transcription, processing, and transport, determine the pattern of messenger RNAs (mRNAs) ${ }^{1}$ delivered to the cytoplasm. The efficiency with which these mRNAs are translated in a cell determines the final pattern of proteins produced. In both human and rabbit reticulocytes, the synthesis of $\alpha$ - and $\beta$-globin proteins is balanced despite an excess of $\alpha$-globin mRNA $(1,2)$. Previous studies, based on indirect detection of mRNA by translational analysis and by identification of nascent peptides on actively translating polysomes, suggest that the balanced synthesis of globin proteins results from both selective sequestration of a portion of the excess $\alpha$-globin mRNA into nontranslated messenger ribonucleoprotein (mRNP) complexes (3) and from more

Address correspondence to Dr. Liebhaber.

Received for publication 29 May 1986.

1. Abbreviations used in this paper: $\mathrm{CDNA}$, complementary DNA; mRNA and rRNA, messenger and ribosomal RNA; mRNP, messenger ribonucleoprotein; SSC, standard saline citrate; $15 \times$ SSPE, $2.23 \mathrm{M} \mathrm{NaCl}$, $150 \mathrm{mM} \mathrm{NaH}_{2} \mathrm{PO}_{4}$, and $15 \mathrm{mM}$ EDTA, pH 7.0.

J. Clin. Invest.

(c) The American Society for Clinical Investigation, Inc.

0021-9738/86/10/1125/05 $\$ 1.00$

Volume 78, October 1986, 1125-1129 efficient ribosome loading of $\beta$-globin mRNA (rabbit [1, 4-6]; human [7-9]). Subsequent studies have shown that human $\alpha$ globin is itself encoded by two separate mRNAs, $\alpha 1$ and $\alpha 2$ (1012 ), which are present in unequal concentrations in the reticulocyte (13-15). As the previous comparisons of $\alpha$ - and $\beta$-globin mRNA distributions were based on protein analysis, they could not detect these two separate $\alpha$-globin mRNAs nor be used to determine their relative contributions to $\alpha$-globin synthesis. In the present report, we determine the translational profiles of the $\alpha 1-, \alpha 2-$, and $\beta$-globin mRNAs by direct detection of each mRNA in pre-80-S mRNPs and across the polysome profile of human reticulocyte lysate. The results of this analysis further define the basis of the balanced expression of the human $\alpha$-and $\beta$-globin genes.

\section{Methods}

Preparation of human reticulocyte lysate. Human reticulocytes were enriched from whole blood of an individual with sickle cell anemia by Percol-Hypaque gradient centrifugation (16). For this fractionation, 1.5 ml of washed packed red cells was applied to a 12-ml gradient containing 35\% Percol (Sigma Chemical Co., St. Louis, MO) and 10\% Hypaque (Winthrop Laboratories, New York, NY) in sterile water and spun at $13,000 \mathrm{rpm}$ in a Sorval SS34 rotor at $4^{\circ} \mathrm{C}$ for $10 \mathrm{~min}$. The top red band was isolated, and then the cells in this fraction were washed three times with $0.15 \mathrm{M} \mathrm{NaCl}$; an aliquot was stained for reticulocytes (Reticulocyte Stain; Becton-Dickinson \& Co., Rutherford, NJ), and the remaining cells were lysed in 2 vol of sterile water and stored in small aliquots at $-70^{\circ} \mathrm{C}$.

Sucrose gradient fractionation of reticulocyte lysate. Sucrose gradient fractionation of reticulocyte lysate was performed essentially as described (17). Briefly, $50 \mu \mathrm{l}$ of reticulocyte lysate was diluted in $100 \mu \mathrm{l}$ of sucrose gradient buffer (17) containing $2 U$ of heparin, layered directly onto 1540\% 5-ml sucrose gradients, and spun as described (17). After centrifugation, the top $500 \mu \mathrm{l}$ of each gradient was removed manually and the gradients were sacrificed by displacing them upwards through an ultraviolet absorbance monitor. A continuous absorbance profile of each gradient at $260 \mathrm{~nm}$ OD was obtained, and fractions corresponding to each peak in the gradient profile were collected.

Preparation of probes. $\alpha$ - and $\beta$-globin complementary DNA (cDNA) inserts were released from the plasmids pMC18 (18) and pSAR6 (19), respectively, by Pst l digestion, resolved on 5\% acrylamide gels, isolated by electroelution, and labeled by nick translation. The labeled DNA was purified by G50 Sephadex column chromatography and heat-melted at $90^{\circ} \mathrm{C}$ for $2 \mathrm{~min}$ before use. DNA oligomers, prepared by the DNA Synthesis Center of the Cancer Center of the Hospital of the University of Pennsylvania, were end-labeled using $\gamma-\left[{ }^{32} \mathrm{P}\right] \mathrm{ATP}$ and polynucleotide kinase (20) and purified by G25 Sephadex column chromatography.

Dot blot hybridization. Each gradient fraction was expanded to $1 \mathrm{ml}$ in sucrose gradient buffer (17). Equal volume aliquots of each gradient fraction were then diluted by the addition of $1 / 2$ vol of $15 \times$ SSPE $(2.23$ $\mathrm{M} \mathrm{NaCl}, 150 \mathrm{mM} \mathrm{NaH}_{2} \mathrm{PO}_{4}$, and $15 \mathrm{mM}$ EDTA, pH 7.0), further diluted 
by the addition of formaldehyde to a final concentration of $6 \%$, heated to $60^{\circ} \mathrm{C}$ for $15 \mathrm{~min}$, and placed on ice. Each sample was further diluted two-fold by the addition of $15 \times$ SSPE and applied in duplicate to a $15 \times$ SSPE-soaked nitrocellulose sheet mounted on a dot blot apparatus (Schleicher and Schuell Inc., Keene, NH). After sample application, filters were air-dried, baked at $80^{\circ} \mathrm{C}$ for $2 \mathrm{~h}$, prehybridized in a hybridization mix containing $50 \%$ formamide $(21)$ for $3 \mathrm{~h}$ at $42^{\circ} \mathrm{C}$, and a single panel of the blot was hybridized with $3 \times 10^{6} \mathrm{cpm}$ of either the $\alpha$-or $\beta$-globin labeled cDNA probe. After hybridization, filters were washed twice for 15 min each in $2 \times$ standard saline citrate (SSC) (20), $0.1 \%$ sodium dodecyl sulfate (SDS) at room temperature, once for $30 \mathrm{~min}$ in $0.03 \times \mathrm{SSC}, 0.1 \%$ SDS at $50^{\circ} \mathrm{C}$, and rinsed in $0.03 \times \mathrm{SSC}$ at room temperature. Before rehybridization of the filters with oligomer probes, the filters were heated to $70^{\circ} \mathrm{C}$ for $20 \mathrm{~min}$ in $50 \%$ formamide hybridization mix and then washed three times in $2 \times$ SSC for 15 min each at room temperature. The absence of residual signal on the filters was confirmed by autoradiography before rehybridization. For hybridization to oligomer probes, filters were prehybridized in hybridization mix without formamide ( $50 \mathrm{mM}$ Hepes, $\mathrm{pH}$ 7.0, $3 \times$ SSC, $18 \mu \mathrm{g} / \mathrm{ml}$ sheared, denatured salmon sperm DNA, $40 \mu \mathrm{g} /$ $\mathrm{ml}$ Escherichia coli transfer RNA, 0.1\% SDS, and 10X Denhardt's [20]) for $3 \mathrm{~h}$ at $48^{\circ} \mathrm{C}$ and then hybridized for $16 \mathrm{~h}$ at $48^{\circ} \mathrm{C}$ to $1 \times 10^{6} \mathrm{cpm}$ of either the $\alpha 1$ - or $\alpha 2$-globin oligomer probe. After hybridization, the filters were washed three times for $15 \mathrm{~min}$ each in $2 \times \mathrm{SSC}$ at $50^{\circ} \mathrm{C}$. Filters were autoradiographed at $-70^{\circ} \mathrm{C}$ on XAR5 film (Eastman Kodak Co., Rochester, NY) with an intensifying screen (Lightening Plus; DuPont Instruments, Wilmington, DE). Autoradiographs were analyzed by soft laser scanning densitometry using a Zeineh scanner (model SL-504-XL; Biomed Instruments, Fullerton, CA) with on-line computer integrating software.

\section{Results}

Washed packed red cells were enriched for reticulocytes on a Percol-Hypaque density gradient (16). An example of the fractionation is shown in Fig. 1 with whole blood (Fig. $1 A$ ) and enriched reticulocytes (Fig. $2 \mathrm{~B}$ ). In the case of the individual studied below, the beginning reticulocyte count was $15 \%$ and the reticulocyte count in the enriched fraction was $85 \%$. A hypotonic lysate prepared from the reticulocyte-enriched fraction was applied to a $15-40 \%$ sucrose gradient. An absorbance profile of the sucrose gradient fractionation is shown in Fig. $2 \mathrm{~A}$. Two fractions, $A$ and $B$, comprise the pre-80S fraction of the reticulocyte lysate. Fraction A contains globin mRNPs and globin mRNA/40S ribosomal subunit complexes, as well as free hemoglobin (which accounts for its high level of ultraviolet absorbance). Fraction B, marked by the ultraviolet absorbance peak of the $60 \mathrm{~S}$ ribosomal subunits (documented by the presence of 28S rRNA, data not shown), also contains globin mRNPs with sedimentation densities in this region. Fractions 1-5 contain actively translating mRNAs with one to five ribosomes per mRNA molecule.

Each of the indicated gradient fractions was analyzed for globin mRNA content by dot blot hybridization (22). $\alpha$-globin mRNA and $\beta$-globin mRNA were detected with near-full-length $\alpha$ - and $\beta$-globin cDNA probes (see Methods). The specificity of these probes for $\alpha$ - or $\beta$-globin mRNA sequences was demonstrated by their specific hybridization to plasmids containing full-length $\alpha$ - and $\beta$-globin cDNAs (Fig. $2 B$ ). Autoradiography of nitrocellulose filters dot blotted with gradient fractions and hybridized with these probes (Fig. $2 B$ ) reveals the distribution of the $\alpha$-and $\beta$-globin mRNAs in the reticulocyte lysate gradient fractions. An accurate direct comparison of $\alpha$ and $\beta$ (or $\alpha 1$ and $\alpha 2)$ mRNA levels is not possible using this data, as the specific activities of the probes and the individual hybridization conditions are not precisely balanced. In the analysis described below,

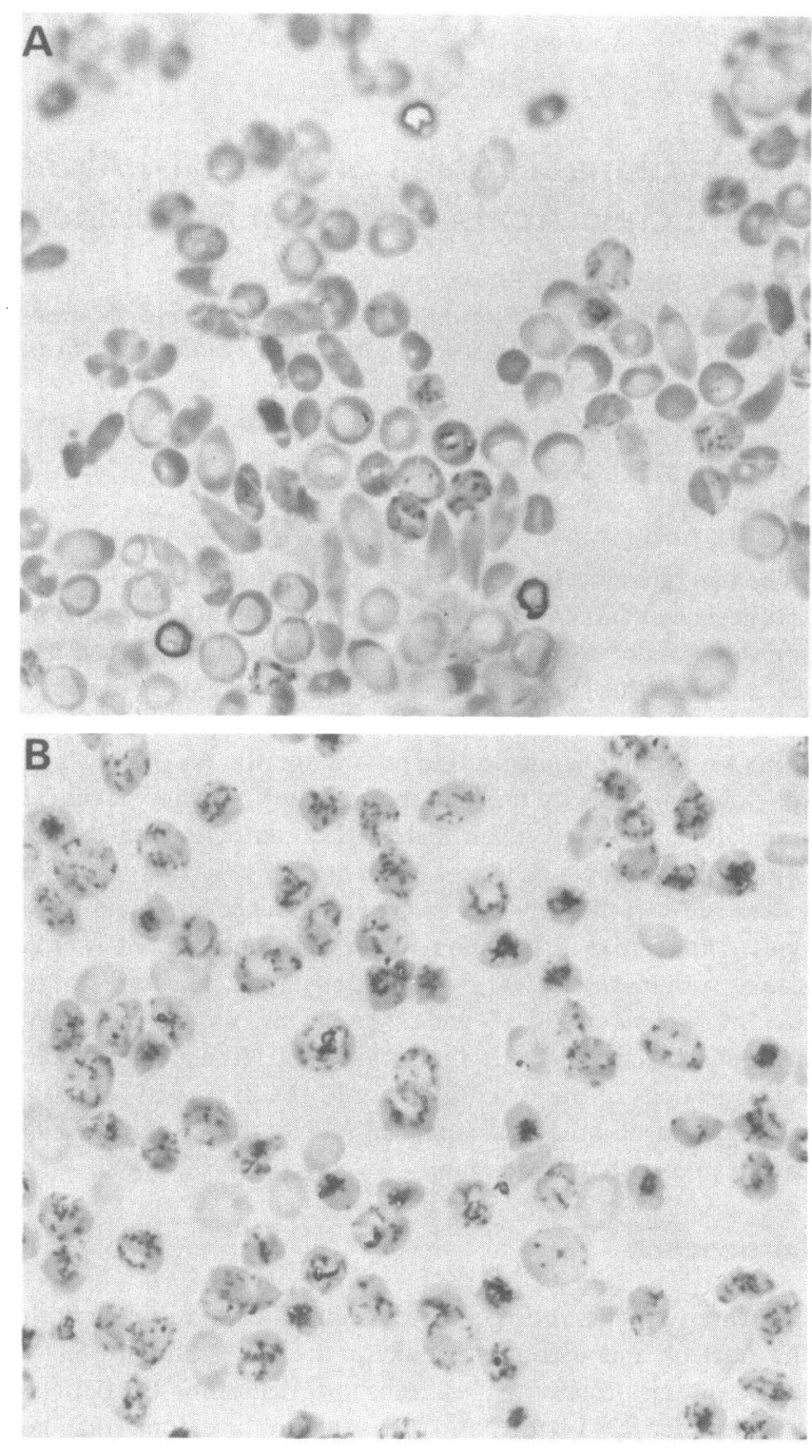

Figure 1. Isolation of reticulocytes from human whole blood. Reticulocyte stains of $(A)$ whole blood, and $(B)$ gradient-enriched reticulocytes.

the translational profiles of the different globin mRNAs are analyzed by comparing the relative distributions of each of the globin mRNAs across the reticulocyte lysate gradient. The exposures shown in Fig. 2, $B$ and $C$, were selected because they are similar in intensity and, therefore, allow a direct visual comparison of the distributions of the mRNAs studied. Densitometric analysis of the autoradiographs in Fig. $2 B$ reveals that $32 \%$ of the total $\alpha$-globin mRNA and $49 \%$ of the total $\beta$-globin mRNA are associated with ribosomes (fractions 1-5), reflecting a preferential sequestration of $\alpha$-globin mRNA into the pre-80S fractions. The distributions of $\alpha$ - and $\beta$-globin mRNAs in the ribosome-associated fractions (1-5) are shown in Fig. $2 D$ (dashed lines). The relative distributions of the $\alpha$ - and $\beta$-globin mRNAs in these gradient fractions were further analyzed by dividing the percentage of $\alpha$-globin mRNA in each fraction by the corresponding percentage of $\beta$-globin mRNA; these ratios are plotted in Fig. $2 E$ (dashed line). The results presented in Fig. 2, $D$ and 
A

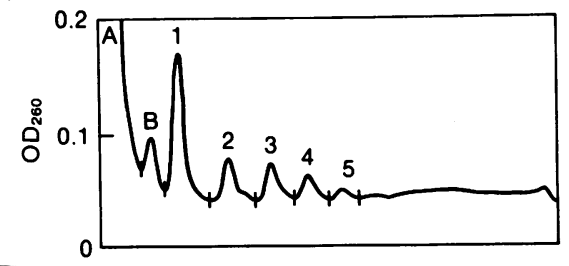

B

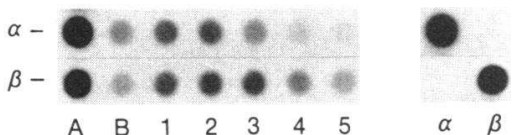

C

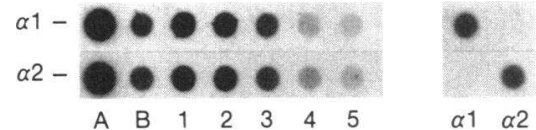

D

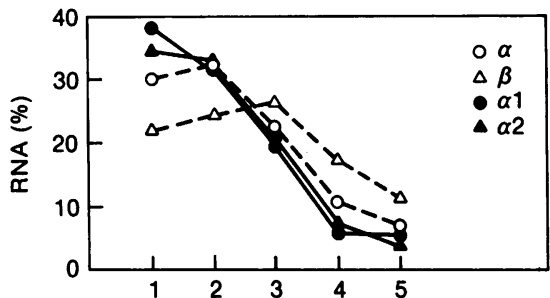

$\mathbf{E}$

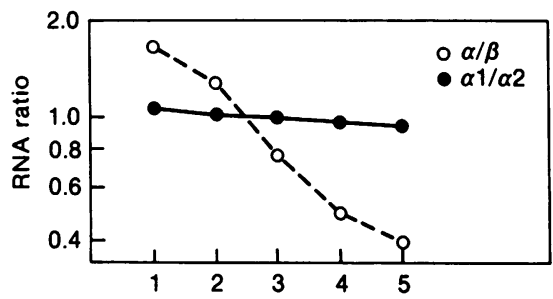

Figure 2. Analysis of globin mRNAs in human reticulocyte lysate. (A) Absorbance profile at $260 \mathrm{~nm}$ OD of sucrose gradient-fractionated human reticulocyte lysate. Vertical lines indicate the extents of each isolated gradient fraction. Pre-80S fractions, $A$ and $B$, and ribosomeassociated fractions, 1-5, are indicated. Fractions labeled 1-5 contain mRNAs associated with 1-5 ribosomes per mRNA molecule, respectively. The top of the gradient is to the left. $(B)$ Dot blot hybridization of the human reticulocyte lysate fractions to $\alpha$ - and $\beta$-globin cDNA probes. Each gradient fraction shown in panel $A$ is dot blotted for detection of globin mRNA content; the identity of each gradient fraction (left autoradiograph) is indicated below each column of dots. Plasmids containing $\alpha$ - and $\beta$-globin cDNAs (pMC18 [18] and pSAR6 [19], respectively) are also dot blotted (right autoradiograph) as controls. The top row of dots $(\alpha)$ is probed with radiolabeled $\alpha$-globin cDNA; the bottom row of dots $(\beta)$ is probed with radiolabeled $\beta$-globin cDNA. (C) Dot blot hybridization of human reticulocyte lysate fractions to $\alpha 1$ - and $\alpha 2$-globin-specific oligomer probes. The same filters described in panel $B$ (left autoradiograph) are reused after elution of the first set of probes (see Methods). Plasmids containing $\alpha 1$ - and $\alpha 2$-globin cDNAs (pH3 $\alpha 1 \mathrm{~B}$ and $\mathrm{pH} 3 \alpha 2 \mathrm{~A}$ [23], respectively) are also dot blotted (right autoradiograph) as controls. The top row of dots $(\alpha l)$ is probed with the radiolabeled $\alpha 1$-globin oligomer; the bottom row of dots $(\alpha 2)$ is probed with the radiolabeled $\alpha 2$-globin oligomer (see Fig. 3 for oligomer probe sequences). $(D)$ Distribution of globin mRNAs in ribosome-associated lysate fractions. For each mRNA studied, the percentage of the total ribosome-associated mRNA (sum of mRNA in fractions 1-5) present in each fraction is plotted. In each case, the percentages of mRNA plotted in fractions $1-5$ totals $100 \%$. The distributions of total $\alpha$-globin mRNA and $\beta$-globin mRNA (data taken from panel $B$ ) are shown in dashed lines; the distributions of $\alpha 1$-globin mRNA and $\alpha 2$-globin mRNA (data taken from panel $C$ ) are shown in solid

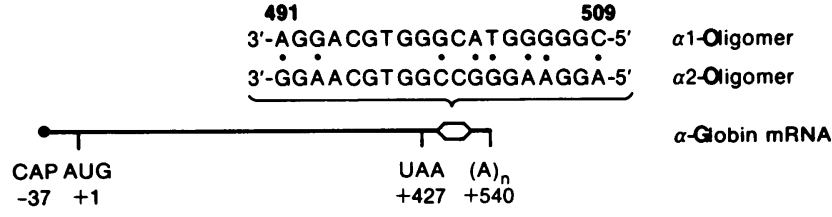

Figure 3. $\alpha 1$ - and $\alpha 2$-globin oligomers. The base sequences and positions of the $\alpha 1$ - and $\alpha 2$-globin oligomers are shown relative to $\alpha$-globin mRNA. The positions of the 5'-terminal cap structure (CAP), initiation codon (AUG), termination codon (UAA), and 3'-polyadenylate tail $\left((\mathrm{A})_{n}\right)$ of $\alpha$-globin mRNA are shown. The position +1 refers to the A of the AUG initiation codon. The region of divergence of the $\alpha 1$ and $\alpha 2$-globin mRNAs within the 3'-nontranslated region is indicated by the open hexagon. Dots between the sequences of the two oligomers indicate positions of sequence mismatch.

$E$, reveal that $\beta$-globin mRNA is distributed on larger polysomes than $\alpha$-globin mRNA.

To specifically detect and quantitate $\alpha 1-$ and $\alpha 2$-globin mRNAs in these lysate fractions, we used DNA oligomer probes complementary to the $3^{\prime}$-nontranslated regions of $\alpha 1$ - and $\alpha 2$ globin mRNA, respectively. The positions and base sequences of these two probes are shown in Fig. 3. The specificity of these probes for the $\alpha 1$ - and $\alpha 2$-globin mRNAs was demonstrated by their selective hybridization to plasmids containing the $3^{\prime}$ nontranslated regions of the $\alpha 1$ - and $\alpha 2$-globin mRNAs, pH $3 \alpha 1 \mathrm{~B}$ $(\alpha 1)$, and pH3 $\alpha 2 \mathrm{~A}(\alpha 2)$ (23), respectively (Fig. $2 C$ ). The nitrocellulose dot blot filters shown in Fig. $2 B$ were rehybridized with these probes after elution of the original probes (see Methods) (Fig. $2 C$ ). $25 \%$ of the total $\alpha 1$-globin mRNA and $26 \%$ of the total $\alpha 2$-globin mRNA were detected in ribosome-associated fractions 1-5. The distributions of $\alpha 1$ - and $\alpha 2$-globin mRNAs in fractions $1-5$ are plotted in Fig. $2 D$ (solid lines). The relative distributions of the $\alpha 1$ - and $\alpha 2$-globin mRNAs in each gradient fraction were further analyzed by dividing the percentage of $\alpha 1$ globin mRNA in each fraction by the corresponding percentage of $\alpha 2$-globin mRNA; these ratios are plotted in Fig. $2 E$ (solid line). This plot reveals that equal percentages of $\alpha 1$-globin mRNA and $\alpha 2$-globin mRNA are present in each of the reticulocyte lysate fractions. In contrast to the different distributions of $\alpha$ - and $\beta$-globin mRNAs in the pre-80S fractions, and across the polysome profile, this analysis demonstrates that the two human $\alpha$-globin mRNAs have identical distributions in reticulocyte lysate.

\section{Discussion}

Balanced synthesis of $\alpha$ - and $\beta$-globin is critical to the normal development and function of erythrocytes. In humans, $\beta$-globin protein is encoded by a single $\beta$-globin gene $(24,25)$, while $\alpha$ globin protein is encoded by two highly homologous $\alpha$-globin genes, $\alpha 1$ and $\alpha 2$ (26-28). The levels of $\alpha$ - and $\beta$-globin protein produced in reticulocytes therefore reflect the relative levels of expression of three separate loci. The relative levels of mRNA

lines. $(E)$ Relative distribution of globin mRNAs in ribosome-associated lysate fractions. The relative percentages of $\alpha$-globin mRNA and $\beta$-globin mRNA (o) and of $\alpha 1$-globin mRNA and $\alpha 2$-globin mRNA (๑) in each ribosome-associated gradient fraction were determined as described in the text and are plotted on a semi-logarithmic scale. 
encoded by each of these genes cannot directly account for the balanced synthesis of $\alpha$-and $\beta$-globin, as each mRNA is expressed at a different level. In the reticulocytes of genetically normal individuals, total $\alpha$-globin mRNA exceeds $\beta$-globin mRNA by 1.2-2.3-fold $(29,30)$, and the $\alpha$-globin mRNA itself is composed of 2-3-fold more $\alpha 2$-globin mRNA than $\alpha 1$-globin mRNA (13$15)$. Balanced synthesis of $\alpha$ - and $\beta$-globin, therefore, is critically dependent on the relative translational efficiencies of the three globin mRNA species. The excess of $\alpha$-globin mRNA must be balanced by more efficient use of $\beta$-globin mRNA, while the relative translational efficiencies of each of the two species of $\alpha$ globin mRNA will determine their relative contributions to net $\alpha$-globin synthesis. While previous studies cited above suggest more efficient translational use of $\beta$-globin mRNA than $\alpha$-globin mRNA, it has not been possible to determine in a similar fashion the relative expression of the two $\alpha$-globin mRNA species, as the protein products of these two mRNAs are identical $(12,14,31)$.

In this study, we compare the translational profiles of $\alpha 1$-, $\alpha 2$-, and $\beta$-globin mRNAs in human reticulocyte lysate by mRNA/cDNA hybridization analysis. This approach allows direct and specific detection of $\alpha 1-, \alpha 2-$, and $\beta$-globin mRNAs in both translationally active polysomes and in pre-80S fractions. Our results, consistent with those of previous studies based on protein analysis, reveal both the preferential sequestration of $\alpha$ globin mRNA into pre-80S fractions and the more efficient ribosome loading of $\beta$-globin mRNA. In contrast, the comparison of $\alpha 1-$ and $\alpha 2$-globin mRNA distributions demonstrates that these two mRNAs have identical translational profiles. This latter result suggests that the two $\alpha$-globin genes are expressed at the same relative levels as their respective mRNA concentrations.

In an earlier report, differences were demonstrated between the translational activities of the $\alpha 1$ - and $\alpha 2$-globin mRNAs isolated from an individual with the genotype $\left(--/ \alpha 1 \alpha 2^{125 P r o}\right)$ (32). In the current comparison, we find no evidence of differential translation of the normal $\alpha 1$ - and $\alpha 2$-globin mRNAs. This discrepancy may be resolved if we postulate that the previously published result may in fact reflect a direct negative effect of the missence mutation, $\alpha 2^{125 \mathrm{Pro}}$, on the translational activity of $\alpha 2$ globin mRNA. The findings in the present report, which suggest the equal translation of the two $\alpha$-globin mRNAs and a consequent dominant role for the $\alpha 2$-globin gene in total $\alpha$-globin synthesis, are supported by our recent genetic analysis of eight individuals with distinct $\alpha$-globin structural mutations; that study demonstrates that structural mutants encoded at the $\alpha 2$-locus are, in general, expressed at a 2-3-fold higher level than those encoded at the $\alpha 1$-locus (33).

The comparison of the translational profiles of the two human $\alpha$-globin mRNAs provides further insight into the molecular pathology of $\alpha$-thalassemia. Deletions or structural mutations affecting either of the $\alpha$-globin gene loci $(\alpha 1$ or $\alpha 2)$ can cause an imbalance in globin synthesis by decreasing the total level of $\alpha$-globin protein produced in erythrocytes (for review, see reference 34). However, the actual degree of $\alpha$-globin deficiency and the consequent severity of the resulting $\alpha$-thalassemia depends on a number of factors. Two well-recognized variables that influence the $\alpha$-thalassemia phenotype are the extent to which the mutation decreases the expression of the affected $\alpha$ globin gene ( $\alpha^{0}$ vs. $\alpha^{+}$thalassemia) and the effect, if any, of the mutation on the expression of the remaining intact $\alpha$-globin genes (15). The results presented in this report suggest a third variable. As there appears to be no difference between the translational activities of the two normal human $\alpha$-globin mRNAs, and since $\alpha 2$-globin mRNA normally comprises the majority of $\alpha$-globin mRNA in reticulocytes, the $\alpha 2$-globin gene locus can be predicted to encode the majority of $\alpha$-globin protein. The two $\alpha$-globin genes, therefore, assume different levels of importance. While a mutation at the $\alpha 1$-globin locus might have only a minor effect on $\alpha$-globin synthesis, an identical mutation at the $\alpha 2$-globin locus would have a greater impact, and would result in a more severe $\alpha$-thalassemia phenotype.

\section{Acknowledgments}

This work was supported in part by grant 1-R01-AM-33975 from the National Institutes of Health (NIH). Susan Shakin is a trainee in the Medical Scientist Training Program, which is supported by grant 5-732GM-07170 from NIH.

\section{References}

1. Lodish, H. F. 1971. Alpha and beta globin messenger ribonucleic acid. Different amounts and rates of initiation of translation. J. Biol. Chem. 246:7131-7138.

2. Bunn, H. F., B. G. Forget, and H. M. Ranney. 1977. Translation of globin mRNA and its control. Human Hemoglobins. W. B. Saunders Co., Philadelphia. 123-126.

3. Jacobs-Lorena, M., and C. Baglioni. 1972. Messenger RNA for globin in the postribosomal supernatant of rabbit reticulocytes. Proc. Natl. Acad. Sci. USA. 69:1425-1428.

4. Hunt, R. T., A. R. Hunter, and A. J. Munro. 1968. Control of haemoglobin synthesis: a difference in the size of the polysomes making $\alpha$ and $\beta$ chains. Nature (Lond.). 220:481-483.

5. Lodish, H. F. 1974. Model for the regulation of mRNA translation applied to haemoglobin synthesis. Nature (Lond.). 251:385-388.

6. Boyer, S. H., K. D. Smith, A. N. Noyes, and M. A. Mullen. 1974. Immunological characterization of rabbit hemoglobin $\alpha$ - and $\beta$-chainsynthesizing polysomes. J. Biol. Chem. 249:7210-7219.

7. Clegg, J. B., D. J. Weatherall, and C. E. Eunson. 1971. The distribution of nascent globin chains on human reticulocyte polysomes. Biochim. Biophys. Acta. 247:109-112.

8. Nathan, D. G., H. F. Lodish, Y. W. Kan, and D. Housman. 1971. Beta thalassemia and translation of globin messenger RNA. Proc. Natl. Acad. Sci. USA. 68:2514-2518.

9. Cividalli, G., D. G. Nathan, and H. F. Lodish. 1974. Translational control of hemoglobin synthesis in thalassemic bone marrow. J. Clin. Invest. 53:955-963.

10. Liebhaber, S. A., M. J. Goossens, and Y. W. Kan. 1980. Cloning and complete nucleotide sequence of human 5 - $\alpha$-globin gene. Proc. Natl. Acad. Sci. USA. 77:7054-7058.

11. Michelson, A. M., and S. H. Orkin. 1980. The $3^{\prime}$ untranslated regions of the duplicated human $\alpha$-globin genes are unexpectedly divergent. Cell. 22:371-377.

12. Liebhaber, S. A., M. Goossens, and Y. W. Kan. 1981. Homology and concerted evolution at the $\alpha 1$ and $\alpha 2$ loci of human $\alpha$-globin. Nature (Lond.). 290:26-29.

13. Liebhaber, S. A., and Y. W. Kan. 1981. Differentiation of the messenger ribonucleic acid transcripts originating from the $\alpha 1$ - and $\alpha 2$ globin loci in normals and $\alpha$-thalassemics. J. Clin. Invest. 68:439-446.

14. Orkin, S. H., and S. C. Goff. 1981. The duplicated human $\alpha$ globin genes: their relative expression as measured by RNA analysis. Cell. 24:345-351.

15. Liebhaber, S. A., F. E. Cash, and D. M. Main. 1985. Compensatory increase in $\alpha 1$-globin gene expression in individuals heterozygous for the $\alpha$-thalassemia-2 deletion. J. Clin. Invest. 76:1057-1064.

16. Vettore, L., M. C. DeMelteis, and P. Zampini. 1980. A new 
density gradient system for the separation of human red blood cells. Am. J. Hematol. 8:291-303.

17. Liebhaber, S. A., F. E. Cash, and S. H. Shakin. 1984. Translationally associated helix-destabilizing activity in rabbit reticulocyte lysate. J. Biol. Chem. 259:15597-15602.

18. Liebhaber, S. A., and K. A. Begley. 1983. Structural and evolutionary analysis of the two chimpanzee $\alpha$-globin mRNAs. Nucl. Acids Res. 11:8915-8929.

19. Liebhaber, S. A., R. F. Trecartin, and Y. W. Kan. 1981. $\beta$-thalassemia in Sardinia is the result of a nonsense mutation. Trans. Assoc. Am. Physicians. 94:88-96.

20. Maniatis, T., E. F. Fritsch, and J. Sambrook. 1982. Molecular Cloning: A Laboratory Manual. Cold Spring Harbor Laboratory, Cold Spring Harbor, New York. 545 pp.

21. Goossens, M., and Y. W. Kan. 1981. DNA analysis in the diagnosis of hemoglobin disorders. Methods Enzymol. 76:805-817.

22. White, B. A., and F. C. Bancroft. 1982. Cytoplasmic dot hybridization: simple analysis of relative mRNA levels in multiple small cell or tissue samples. J. Biol. Chem. 257:8569-8572.

23. Liebhaber, S. A., and F. E. Cash. 1985. Locus assignment of $\alpha$ globin structural mutations by hybrid-selected translation. J. Clin. Invest. 75:64-70.

24. Flavell, R. A., J. M. Kooter, E. DeBoer, P. F. R. Little, and R. Williamson. 1978. Analysis of the $\beta-\delta$-globin gene loci in normal and $\mathrm{Hb}$ Lepore DNA: direct determination of gene linkage and intergene distance. Cell. 15:25-41.

25. Fritsch, E. F., R. M. Lawn, and T. Maniatis. 1980. Molecular cloning and characterization of the human $\beta$-like globin gene cluster. Cell. 19:959-972.

26. Orkin, S. 1978. The duplicated human $\alpha$-globin genes lie close together in cellular DNA. Proc. Natl. Acad. Sci. USA. 75:5950-5954.

27. Embury, S. H., R. V. Lebo, A. M. Dozy, and Y. W. Kan. 1979. Organization of the $\alpha$-globin genes in the Chinese $\alpha$-thalassemia syndromes. J. Clin. Invest. 63:1307-1310.

28. Lauer, J., C.-K. J. Shen, and T. Maniatis. 1980. The chromosomal arrangement of human $\alpha$-like globin genes: sequence homology and $\alpha$ globin gene deletions. Cell. 20:119-130.

29. Hunt, D. M., D. R. Higgs, J. M. Old, J. B. Clegg, D. J. Weatherall, and G. W. Marsh. 1980. Determination of alpha thalassemia phenotypes by messenger RNA analysis. Br. J. Haematol. 45:53-64.

30. Forget, B. G., D. Housman, E. J. Benz, Jr., and R. P. McCaffrey. 1975. Synthesis of DNA complementary to separated human alpha and beta globin messenger RNAs. Proc. Natl. Acad. Sci. USA. 72:984-988.

31. Földi, J., M. Cohen-Solal, C. Valentin, Y. Blouquit, S. R. Hollan, and J. Rosa. 1980. The human alpha-globin gene: the products of the duplicated genes are identical. Eur. J. Biochem. 109:463-470.

32. Liebhaber, S. A., and Y. W. Kan. 1982. Different rates of mRNA translation balance the expression of the two human $\alpha$-globin loci. $J$. Biol. Chem. 257:11852-11855.

33. Liebhaber, S. A., F. E. Cash, and S. K. Ballas. 1986. Human $\alpha-$ globin gene expression: the dominant role of the $\alpha 2$-locus in mRNA and protein synthesis. J. Biol. Chem.

34. Higgs, D. R., and D. J. Weatherall. 1983. Alpha-thalassemia. Curr. Top. Hematol. 4:37-97. 